\title{
Avaliação da qualidade de vida urbana nos condomínios horizontais da cidade de João Pessoa, PB
}

\author{
Evaluation of the quality of urban life in horizontal \\ condominiums in the city of João Pessoa, $P B$
}

\section{Anneliese Heyden Cabral de Lira José Augusto Ribeiro da Silveira Edson Leite Ribeiro Milena Dutra da Silva Luciana Andrade dos Passos}

\section{Resumo}

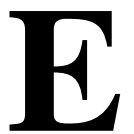

ste artigo tem como tema a qualidade de vida urbana nos condomínios horizontais localizados na cidade de João Pessoa, PB. Essa modalidade residencial tem se proliferado e tem movimentado consideravelmente $\mathrm{o}$ mercado imobiliário local, com a premissa de que a "qualidade de vida" no interior dos condomínios é superior ao padrão urbano encontrado na cidade extramuros. No entanto, não existem pesquisas locais a partir de métodos científicos que mensurem essa mencionada "qualidade de vida". Desse modo, com base no método "Índice da Qualidade de Vida Urbana de João Pessoa" (IQVUJP), este estudo procura preencher tal lacuna ao investigar a qualidade de vida urbana nesses empreendimentos, com ênfase em seu entorno e sua relação com a tessitura urbana. Os principais resultados desta pesquisa apontam para a importância da localização na determinação da qualidade de vida urbana, uma vez que os atributos locacionais traduzem as facilidades ou deficiências das oportunidades e dos acessos urbanos. A investigação também demonstrou que a qualidade de vida urbana aferida não condiz com o que é propagado pela mídia e pelo mercado imobiliário local, que atribui valores positivos às áreas consideradas distantes com baixa densidade urbana e ao isolamento físico e social.

Anneliese Heyden Cabral de

Faculdades Integradas de Patos Patos - PB - Brasil

José Augusto Ribeiro da Silveira Universidade Federal da Paraíba João Pessoa - PB - Brasil

Edson Leite Ribeiro Ministério das Cidades Brasília - DF - Brasil

Milena Dutra da Silva Universidade Federal de Alagoas Penedo - AL - Brasil

Luciana Andrade dos Passos Universidade Federal da Paraíba João Pessoa - PB - Brasil

Recebido em 28/01/16 Aceito em 26/03/17
Palavras-chave: Condomínio horizontal. Qualidade de vida urbana. Facilidades urbanas. Acessibilidade.

\section{Abstract}

The aim of this article is to analyse the quality of urban life in horizontal condominiums located in the city of João Pessoa, PB. This housing modality has proliferated and considerably changed the local real estate market, using the premise that the "quality of life" inside the condominiums is supposedly higher than the urban standard found in the city outside its walls. However, there is no local research that measures this so-called "quality of life" by using specific and scientific methods. Therefore, based on the "Quality of Urban Life Index in the city of João Pessoa" (QULI-JP) method, this study aims at filling this gap, by investigating the quality of life in the condominiums, paying special attention to their surroundings and relationship with the urban fabric. The main results in this research show how important the location is to determine the quality of urban life, as the location attributes translate the facilities and deficiencies of opportunities and urban access. The investigation also demonstrates that the quality of urban life measured does not match what is advertised by the media and the local real estate market, which places high value to areas considered distant, with low urban density which are physically and socially isolated.

Keywords: Horizontal condiminium. Quality of urban life. Urban facilities. Accessibility. 


\section{Introdução}

Desde a década de 1990 observa-se uma crescente preocupação com a qualidade de vida, originada principalmente devido ao crescimento acelerado e "caótico" das grandes cidades e suas consequências, como o agravamento das desigualdades sociais e da distribuição de bens e serviços, e o aumento da poluição, do congestionamento e da degradação do meio ambiente (SANTOS; MARTINS, 2007). Esse quadro evidencia, conforme Nahas (2005), a atual incapacidade do modelo de desenvolvimento de gerir mais e melhor qualidade de vida.

\section{[...] além de não se conseguir erradicar a ignorância, a violência e a pobreza, agravou-se a situação social e ambiental $e$ consolidaram-se, especialmente nas grandes cidades, enormes disparidades sócio-espaciais em todos os aspectos. (NAHAS, 2005, p. 1).}

Diante desse contexto, a sensibilidade social sobre esses temas tem aumentado, fazendo-se presente em debates sobre as políticas urbanas e administração das cidades e incorporando-se às estratégias dos demais agentes responsáveis pela produção do espaço urbano.

Porém, é importante o entendimento do que é "qualidade de vida", principalmente no contexto contemporâneo, no qual o segmento imobiliário é produzido e distribuído pelas leis de mercado, por intermédio da "utopia materialista de consumo" (BUARQUE, 1993), seduz a população com propostas que não preenchem os requisitos para uma real qualidade de vida.

O conceito de qualidade de vida divulgado na mídia e no mercado imobiliário está associado comumente a condições privilegiadas, ligadas a um alto padrão de vida ou à possibilidade de resolução individual de condições de acessibilidade à oferta de bens e serviços, de amenização e de oferta de lazer, para quem possa pagar por tal. $\mathrm{Na}$ questão espacial urbana atribuem-se valores positivos a áreas isoladas e distantes do contexto urbano. No entanto, de acordo com literatura a respeito do tema, vários conceitos sobre qualidade de vida e qualidade de vida urbana estão diretamente relacionados a uma condição de harmonia social e ambiental, estando, portanto, intrinsecamente ligados à justiça social (ALMEIDA, 1997; RIBEIRO, 2006; LEITE; AWAD, 2012). Quando considerada a qualidade urbana na temática referida, são avaliadas as disponibilidades e oportunidades que a localização urbana oferece para a habitação e o cotidiano social (EL DIN et al., 2013).
Nesse viés, surgem alternativas habitacionais, como os condomínios horizontais, que buscam distanciar-se dos problemas urbanos e suas implicações na qualidade de vida. Os condomínios horizontais caracterizam uma tipologia habitacional que vem se expandindo em todo o mundo e são produzidos frequentemente devido à união de vários fatores: a mencionada falta de qualidade de vida nas cidades, a insegurança, a ineficiência da gestão pública, a massificação da cultura do medo, a atuação do mercado imobiliário, que promove a oferta de um "novo modo de viver", e a procura por grande parcela da sociedade de espaços que transpareçam uma imagem de "qualidade de vida".

Essa modalidade residencial atrai seus moradores não apenas por suas características internas, mas também pelo acesso a benefícios tais como privacidade e privatização dos serviços de segurança, e a valores simbólicos, como a natureza e o status. Somam-se, ainda, a possibilidade de retornar a morar em casas e a paisagem predominantemente suburbana atrelada às supostas expectativas de um "modo de vida saudável", o que acaba direcionando a implantação desses empreendimentos para áreas da cidade consideradas mais amenas, "periféricas", e com maior estoque de terrenos. Assim, tais empreendimentos apoiam-se nesses aspectos, que supostamente conferem maior "qualidade de vida", utilizando-os como âncora de atratividade de marketing e vendas.

No entanto, o desdobramento dessas estratégias de marketing, no espaço urbano e na sociedade, leva muitos pesquisadores da matéria urbana a criticarem a produção crescente dos condomínios horizontais. Os fatores mais mencionados são a forma como redefinem os espaços públicos e privados, como restringem seu acesso, segregando parcelas da população, e como auxiliam nos processos de fragmentação e prolongamento das bordas urbanas (REIS, 2006; CALDEIRA, 2000; LEITE; AWAD, 2012).

Não obstante, na cidade de João Pessoa, PB, essa modalidade residencial tem se expandido e movimentado o mercado imobiliário local, utilizando a premissa de que a qualidade de vida na célula interna, que é o condomínio, é bem superior ao padrão urbano encontrado na cidade extramuros

Diante do exposto, o objetivo central deste artigo é avaliar a qualidade de vida urbana dos condomínios horizontais da cidade de João Pessoa, capital do estado da Paraíba, por meio do método 
"Índice de Qualidade de Vida Urbana de João Pessoa" (IQVU-JP), elaborado por Ribeiro (2001). Esta avaliação buscou maior ênfase na eficiência dos atributos urbanos, com base no entorno dos condomínios e sua relação com a tessitura urbana.

Atualmente, na cidade de João Pessoa, existem 11 condomínios horizontais ${ }^{1}$ de alta renda. A ocorrência desses empreendimentos, apesar de ter sido iniciada na década de 1980, se firmou com maior intensidade a partir do ano de 2002, movimentando consideravelmente o mercado imobiliário local.

Os condomínios horizontais tendem a se concentrar na porção sul da faixa litorânea, em setores deslocados da malha urbana consolidada (bairros Altiplano, Portal do Sol e Ponta do Seixas), mas considerados privilegiados do ponto de vista das amenidades, da atratividade ao uso residencial e de uma expectativa de valorização futura. Por outro lado, estudos tais como os de Lira (2012) e Cruz e Morais (2016) relatam que esses setores destacam-se pela precariedade do provimento de comércio e serviços locais, pela segregação social envolvendo classes mais ricas e pelas limitações de acessibilidade, pois são espaços pouco integrados. Além disso, apesar de a maioria desses empreendimentos ser de grande porte, são quase que exclusivamente residenciais, não apresentando significativo atendimento comercial ou de prestação de serviço.

Os objetos de estudo desta pesquisa correspondem a condomínios horizontais de alta renda, localizados mais especificamente nos bairros Portal do Sol e Bairro dos Estados, na cidade de João Pessoa. Entre os condomínios existentes, os objetos de estudo empírico se limitaram a três empreendimentos para representar o panorama local dessa modalidade residencial: Condomínio Cabo Branco Residence Privé (CBRP), Condomínio Villas do Farol e Condomínio Alphaville Fazenda Boi Só (Figura 1). Tal seleção foi fundamentada mediante critérios de localização, dimensão e densidade populacional, tendo-se optado, portanto, pelos condomínios mais representativos nesses aspectos.

\footnotetext{
${ }^{1}$ Conforme registros informados pela Prefeitura Municipal de João Pessoa, a maioria desses empreendimentos foi inicialmente licenciada como loteamento e, mesmo reconhecidos como tal, foram erguidos muros, promovendo seu fechamento integral. Porém, posteriormente, efetivaram os procedimentos de remembramento para regularização junto à municipalidade, culminando nos reconhecimentos oficiais e registros como condomínios privados (ANDRADE; VIDAL, 2012).
}

\section{Aporte teórico}

\section{Qualidade de vida}

O conceito desenvolvido por Wilheim (2003, p. 133) define que a qualidade de vida é "[...] o grau de satisfação e sensação do bem-estar do indivíduo [...]", que depende basicamente de conjuntos de fatores objetivos e externos e de fatores subjetivos e internos.

Os fatores objetivos e externos podem ser entendidos como necessidades fundamentais $\mathrm{e}$ essenciais, que apreciam, além dos direitos básicos, alguns aspectos socioculturais e o estágio de desenvolvimento da sociedade, como o direito à alimentação, à saúde, à educação básica, à obtenção de renda, à segurança e às liberdades individuais mínimas.

Os fatores subjetivos e internos são entendidos como a ampliação dos anseios fundamentais, que constituem a evolução qualitativa do conceito de qualidade de vida e correspondem à ampliação da região de oportunidades de cada indivíduo. Conforme Wilheim (2003), a "região de oportunidades" pode ser definida por fatores como sentimentos de realização pessoal e social, de saúde, vitalidade, bem-estar, segurança e liberdade, e é determinada por um conjunto de demandas variáveis, de acordo com a posição econômica e social do indivíduo.

Pode-se observar que muitos fatores considerados na região de oportunidades estão correlacionados ao nível socioeconômico. Segundo Ribeiro (2009), isso ocorre porque a maioria desses modelos de mensuração foi pensada também para avaliar o nível de desenvolvimento econômico de uma região, baseando-se em ideias econômicas liberais.

A qualidade de vida, embora aparente ser um conceito intuitivo, é uma temática complexa, pelas diferentes interpretações, percepções e por sua própria subjetividade (LIRA, 2012; HASANI;MOSAYEBI; HASANI, 2016). Existe uma vasta literatura e uma multiplicidade de conceitos que buscam de forma objetiva reunir um conjunto de indicadores que sintetizem qualitativamente a satisfação de indivíduos no contexto onde vivem. Por isso mesmo, as pesquisas têm avançado no sentido de considerar os aspectos sociais, ambientais, políticos, econômicos e culturais particulares a cada região/amostra. 
Figura 1 - Localização dos condomínios horizontais de alta renda da cidade de João Pessoa e os tomados como objeto de estudo

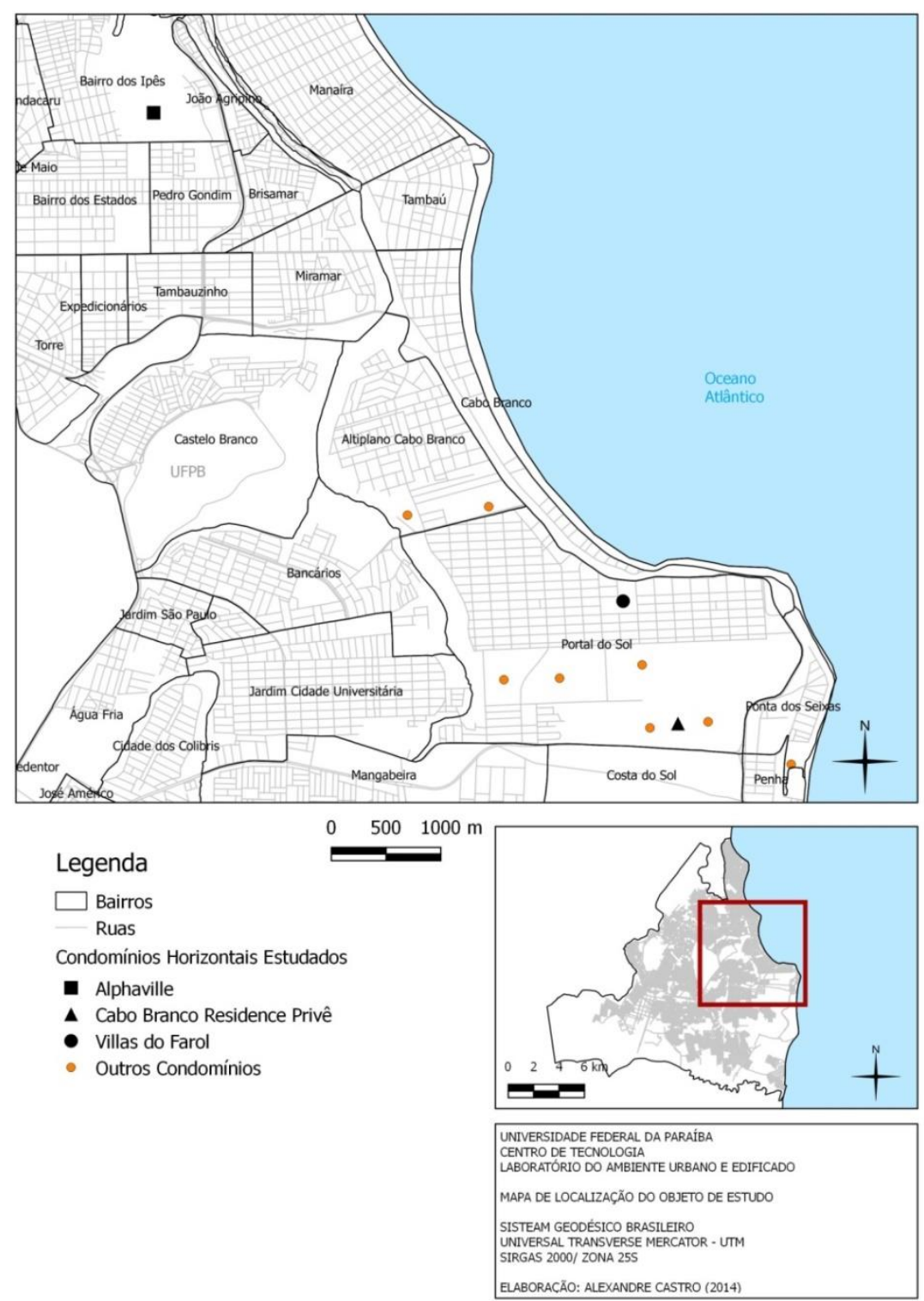

\section{Qualidade de vida urbana}

Na qualidade de vida urbana, o foco é a cidade, e não exclusivamente o indivíduo, como remete o conceito de qualidade de vida. Pensa-se nas pessoas inseridas no contexto urbano, permeando, consoante Nahas et al. (1998), o conceito de qualidade de vida urbana entre o de "qualidade de vida" e o de "qualidade ambiental".

Ribeiro (2009) define o conceito da qualidade de vida urbana a partir da atribuição dos aspectos específicos da vida e das necessidades urbanas, em função da divisão social do trabalho, dos padrões de relações sociais, das formas de acesso e obtenção de bens e serviço e das próprias estratégias de sobrevivência dentro do tecido físico e social da cidade. Resumidamente, conforme o autor, considera-se a qualidade de vida urbana a capacidade interna das estruturas e do aparato urbano para o atendimento da qualidade de vida tipicamente urbana.

Em síntese, aos elementos essenciais de qualidade de vida, no sentido humano, acrescentam-se as novas necessidades e as facilidades decorrentes de sua localização urbana em relação aos demais elementos de sua estrutura.

Essa temática tem sido foco de vários estudos internacionais e nacionais, bem como ferramenta de gestão e planejamento urbano de cidades brasileiras e estrangeiras. Observam-se métodos e uma diversidade de fatores e de "pesos" atribuídos 
a cada fator, ajustados à cultura local ou à condição social. Porém, dada a heterogeneidade do contexto urbano, nem sempre o resultado advindo desses indicadores corresponde, em sua totalidade, à realidade do recorte espacial analisado, mesmo quando mensuradas escalas territoriais reduzidas.

Predomina uma visão do espaço urbano como continente, no qual se avalia o desempenho do todo, em detrimento de avaliações específicas de suas partes, em especial, na escala dos cidadãos que o habitam. (MATSUI, 2016, p. 4).

Ademais, na maioria das vezes não é considerado, de forma prioritária, o conhecimento dos resultados pela população observada para que se tenha um confronto entre os resultados metaanalíticos e a percepção daqueles que vivenciam os aspectos avaliados.

$\mathrm{Na}$ formulação da proposta pelo Sistema de Monitoramento da Qualidade de Vida do Município do Porto, em Portugal, segundo Santos e Martins (2007), se ponderou a Qualidade de Vida Urbana a partir de quatro domínios e subtemáticas afins a cada um desses domínios (Figura 2).

O Índice de Qualidade de Vida dos Municípios Brasileiros (IQVU-Br) foi elaborado para gerar um índice de abrangência nacional e auxiliar o Ministério das Cidades na identificação de prioridades espaciais e setoriais e na elaboração de projetos e políticas. Segundo Nahas (2011), esse sistema de avaliação é composto de indicadores urbanos georreferenciados (49 indicadores ao total) em cada um dos 5.560 municípios brasileiros. O objetivo desses indicadores é avaliar a possibilidade espacial de acesso à oferta de serviços e recursos referentes às variáveis comércio e serviços; cultura; economia; educação; habitação; saúde; instrumentos de gestão urbanística; participação e organização sociopolítica; meio ambiente urbano; segurança pública; e transportes.
Ribeiro (2001), ao elaborar o Índice de Qualidade de Vida Urbana da cidade de João Pessoa (IQVUJP), considerou o conjunto de possibilidades e metodologias adotadas em outras cidades brasileiras, buscando a simplificação e a integração em três grupos de indicadores qualitativos urbanos e mais um grupo de indicadores de qualidade habitacional. Tais grupos foram adotados a partir da observação dos seguintes aspectos nas metodologias existentes que investigou e nas conclusões até então consensuais a seguir:

(a) os elementos sempre presentes e consensuais em todas as experiências e métodos observados foram Habitação, Saúde, Renda e Educação;

(b) o item Habitação, no conjunto das metodologias estudadas, comportava uma importância de $30 \%$ em média em relação ao total da qualidade de vida urbana;

(c) os itens Renda, Educação e Saúde constituíam os elementos motivadores para o advento das migrações das populações das áreas rurais para as áreas urbanas, devendo sua acessibilidade e sua oferta ter um peso importante no modelo, sendo, portanto inserido em dois elementos que constituíram a metodologia: sua oferta, através do Indicador de Qualidade das Facilidades Urbanas, e sua acessibilidade, medida por meio do Indicador de Qualidade das Acessibilidades Urbanas; e

(d) vários estudos conferiam, também, ampla importância aos aspectos ambientais urbanos. Dessa forma, introduziu-se na metodologia o Indicador de Qualidade da Ambiência Urbana, incluindo o ambiente físico e o social.

Este índice tem sido aplicado para mensurar recortes espaciais, tais como conjuntos habitacionais, loteamentos e condomínios, assim como unidades urbanas (bairros) de João Pessoa, com a possibilidade de atualização periódica de curto prazo.

\section{Figura 2 - Esquema da Qualidade de Vida Urbana, com seus quatro domínios e várias temáticas}
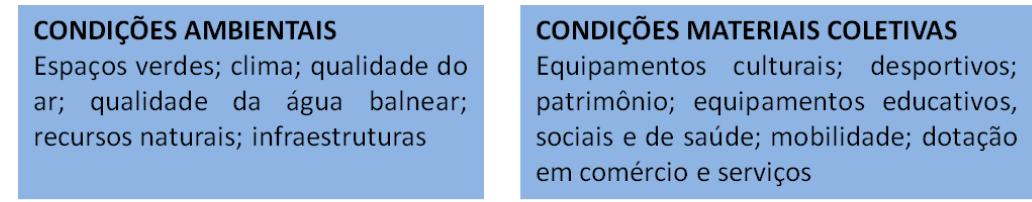

QUALIDADE DE VIDA URBANA

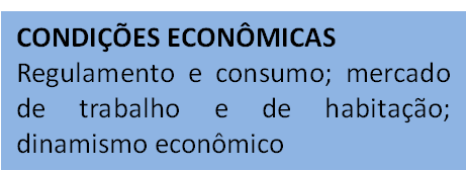

Fonte: Santos e Martins (2007).

Fonte: Santos e Martins (2007).

\section{SOCIEDADE}

Dinâmica cultural; educação; população; segurança; saúde; participação cívica; problemas sociais 


\section{Método}

A pesquisa utilizou como metodologia principal para mensuração o Índice de Qualidade de Vida Urbana de João Pessoa (IQVU-JP), elaborada por Ribeiro (2001). Tal método aborda aspectos operacionais referentes à diagnose analítica, descritiva e quantitativa da qualidade de vida urbana de determinado recorte urbano, admitindose microespacialidades ou unidades urbanas. Esse índice foi escolhido por apresentar grupos de indicadores intrínsecos às particularidades regionais em termos geográficos, sociais e físicos da cidade na qual estão implantados os objetos de estudo $^{2}$. Ademais, o índice também apresenta abordagem ajustada a condutas vistas como sustentáveis e de equidade social que refletem os apontamentos da literatura pertinente ao tema.

Esse índice advém da junção do Índice de Qualidade Urbana aplicado à cidade de João Pessoa (IQU-JP) a alguns aspectos do desenvolvimento humano, como o Índice de Desenvolvimento Humano (IDH), levando em consideração indicadores relativos à educação e à longevidade. O IQU-JP (Figura 3), por sua vez, é obtido a partir da integração de três grupos de indicadores qualitativos urbanos e mais um grupo de indicador de qualidade habitacional. Cada grupo detém, dentro do índice geral, peso equivalente à dimensão observada a partir da relevância e atribuição de outras metodologias e da percepção da população local. Assim, tem-se a seguinte ponderação:

(a) o Indicador de Qualidade Habitacional detém $30 \%$ da importância total do índice; (b) o Indicador de Facilidades Urbanas, 30\%;

(c) o Indicador de Acessibilidades Urbanas, 20\%; e

(d) o Indicador de Ambiência Urbana, 20\%.

Dessa forma, com o arranjo composto por esses quatro grupos de indicadores, tratados conjuntamente e de forma ponderada, dá-se a pontuação do IQU-JP, a partir da seguinte Equação 1:

$0,3($ Iqha $)+0,3($ Iqfa $)+0,2($ Iace $)+0,2($ Iaam $)=$ IQU-JP

Eq. 1

O IQVU-JP, por sua vez, é obtido a partir da Equação 2:

IQVU-JP $=2 \cdot[0,3($ Iqha $)+0,3($ Iqfa $)+0,2($ Iace $)+$ $0,2($ Iaam $)]+[($ IDH-E+IDH-L $) / 2] / 3 \quad$ Eq. 2

Onde:

IQVU-JP - Índice de Qualidade de Vida Urbana aplicado à cidade de João Pessoa;

Iqha - Indicador de Qualidade Habitacional;

Iqfa - Indicador de Facilidades Urbanas;

Iace - Indicador de Acessibilidades Urbanas;

Iaam - Indicador de Ambiência Urbana;

IDH-E - Indicador de Desenvolvimento Humano relacionado à Educação; e

IDH-L - Indicador de Desenvolvimento Humano relacionado à Longevidade.

Conforme a Figura 4, esses grupos de indicadores principais contêm dentro de si uma série de indicadores secundários e terciários, que formam sua composição final.

Figura 3 - Esquema do Índice de Qualidade de Vida Urbana aplicado à cidade de João Pessoa, PB

\begin{tabular}{|c|c|}
\hline $\begin{array}{l}\text { QUALIDADE HABITACIONAL } \\
\text { Densidade, ocupação e conforto; } \\
\text { Qualidade estrutural e higiene; } \\
\text { Infraestrutura e instalações }\end{array}$ & $\begin{array}{l}\text { QUALIDADE DAS FACILIDADES } \\
\text { URBANAS } \\
\text { Infraestrutura urbana; Equipamentos } \\
\text { urbanos; Serviços urbanos }\end{array}$ \\
\hline \multicolumn{2}{|c|}{ QUALIDADE DE VIDA URBANA } \\
\hline $\begin{array}{l}\text { QUALIDADE DAS ACESSIBILIDADES } \\
\text { Articulações entre usos do solo e } \\
\text { oportunidades; Qualidade do } \\
\text { sistema de circulação; Qualidade de } \\
\text { sistema de transportes }\end{array}$ & $\begin{array}{l}\text { QUALIDADE DA AMBIÊNCIA } \\
\text { URBANA } \\
\text { Qualidade do ambiente físico; } \\
\text { Qualidade do ambiente social; } \\
\text { Qualidade da percepção ambiental }\end{array}$ \\
\hline
\end{tabular}

Fonte: Ribeiro (2001).

\footnotetext{
2 Segundo Ribeiro (2001), a prospecção de dados que alimentam a construção desses indicadores foi feita a partir de fontes institucionais locais, observação e mensuração de campo ou através da interpretação de imagens obtidas remotamente, dependendo da característica das informações. Os dados obtidos institucionalmente através de outra fonte receberam a complementação ou atualização com dados obtidos pela observação de campo.
} 
Figura 4 - Índice de Qualidade de Vida Urbana aplicado a João Pessoa (IQVU-JP) e o grupo de indicadores e índices que o compõe

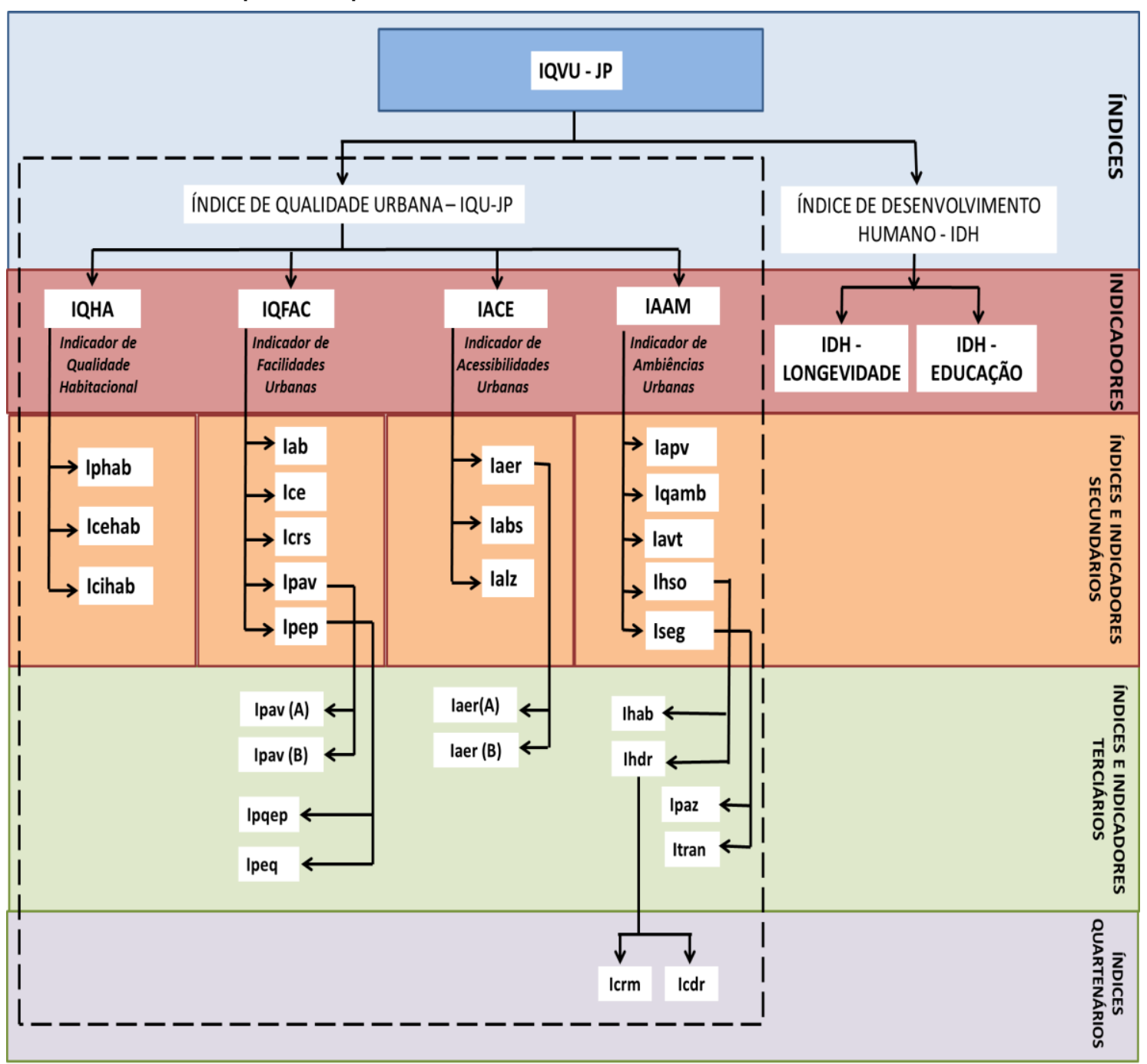

O grupo do Indicador de Qualidade Habitacional (Iqha) avalia a salubridade e conforto, qualidade estrutural e qualidade infraestrutural ligada à unidade habitacional, e é formado pela média ponderada de três indicadores secundários (Equação 3):

Iqha $=\mathbf{0 , 3}($ Ipqhab $)+\mathbf{0 , 3}($ Icehab $)+\underset{0,4}{(\text { Icihab })}$

Onde:

Ipqhab = índice de saturação ou de pessoas por quarto;

Icehab = índice de condições estruturais habitacionais; e

Icihab = índice de condições infraestruturais habitacionais.
Por sua vez, o Indicador de Facilidades Urbanas (Iqfa) afere as infraestruturas, os equipamentos e os serviços urbanos. Para tanto, consideram-se subíndices voltados para o contexto micro e macro urbano, e não para unidade habitacional, tais como:

Iab = Índice de abastecimento de água do conjunto de domicílios do bairro;

Ice $=$ Índice de coleta de esgotos do conjunto de domicílios do bairro;

Icrs = Índice de coleta de resíduos sólidos, do conjunto de domicílios do bairro;

Ipav = Índice de pavimentação viária do conjunto de domicílios do bairro; e

Ipep = Índice de proximidade de equipamentos públicos relativo a uma média do conjunto de provimentos acessível a cada bairro. 
Assim, o resultado do Iqfa é obtido a partir da Equação 4:

Iqfac $=0,3($ Iab $)+0,2($ Ice $)+0,1($ Ipav $)+0,2($ Icrs $)$ $+0,2$ (Iрер)

Eq. 4

O terceiro grupo é composto do Indicador de Acessibilidades Urbanas (Iace), que indica os níveis de facilidade de acesso físico às oportunidades de trabalho, estudo, compras e lazer, promovido pela articulação entre as diversas opções e uso residencial e pelos elementos facilitadores de deslocamento e mobilidade. Para obtê-lo, Ribeiro (2001) utilizou um conjunto de indicadores terciários, ponderados conforme a Equação 5:

$$
\text { Iace }=\mathbf{0 , 5}(\text { Iaer })+\mathbf{0 , 3}(\text { Iabs })+\mathbf{0 , 2}(\text { Ialz }) \quad \text { Eq. } 5
$$

O Iaer (indicador de acessibilidades físicas a áreas geradoras de oferta de emprego, possibilidades de renda, escolas e bens e serviços) é obtido pela soma ponderada de dois sub-indicadores que avaliam as distâncias ao centro principal, bem como aos centros secundários mais importantes. $\mathrm{O}$ próximo índice é o Iabs (índice de acessibilidade ao provimento facilitado de bens e serviços), que utiliza o critério de tempo de acesso a um centro terciário (ou distrital), ou centro de nível superior (principal ou secundário). E, por fim, o índice Ialz (critério de acessibilidade a áreas de lazer públicas).

O último dos grupos de indicadores da metodologia é o Indicador de Ambiência Urbana (Iaam), que mensura a qualidade perceptiva ambiental (física e social), levando em consideração também a presença de elementos amenizadores ambientais e a ausência ou baixa ocorrência de fatores físico-ambientais impactantes negativos. Este indicador é obtido a partir da Equação 6:
Iaam $=0,1($ Iapv $)+0,3($ Iqamb $)+0,1($ Iavt $)+$ $\mathbf{0 , 1}($ Ihso $)+\mathbf{0 , 4}($ Iseg) $\quad$ Eq. 6

Onde:

Iapv = índice de proximidade ou presença sensível de parques, áreas verdes ou áreas de valor cênico e praias;

Iqamb = indicador de ocorrência de elementos nocivos à qualidade ambiental;

Iavt = índice de áreas verdes tratadas por habitante;

Ihso = índice de homogeneidade social; e

Iseg = índice de segurança urbana.

Cada indicador ou índice secundário ou terciário pertencente a este método é obtido a partir de critérios específicos estabelecidos em faixas percentuais e respectivas graduações de pontuações. Por exemplo, o Iab (índice de abastecimento de água), concernente ao Indicador de Facilidade Urbanas, é mensurado pela observação da faixa de percentual de domicílios servidos por água tratada, tal como demonstra a Tabela 1.

Por fim, a partir deste conjunto de indicadores secundários e terciários, têm-se uma análise da qualidade urbana em cada segmento ou recorte espacial da cidade de João Pessoa. Este índice seria, portanto, o resultado qualitativo proporcionado pelo conjunto de potencialidades positivas em cada segmento do espaço urbano, com a dedução de suas externalidades negativas, já introduzidas no próprio modelo. Para um critério de avaliação comparativa, estabeleceu-se que os resultados do IQU-JP e do IQVU-JP apresentassem a avaliação qualitativa apresentada na Tabela 2.

Tabela 1 - Critérios para a elaboração do índice de abastecimento de água - lab

\begin{tabular}{|c|c|}
\hline Critério & Pontuação \\
\hline $\begin{array}{l}\text { Percentual de habitações com abastecimento de água entre } 91 \% \text { e } \\
100 \%\end{array}$ & 1,0 \\
\hline $\begin{array}{l}\text { Percentual de habitações com abastecimento de água entre } 81 \% \text { e } \\
90 \%\end{array}$ & 0,7 \\
\hline $\begin{array}{l}\text { Percentual de habitações com abastecimento de água entre } 61 \% \text { e } \\
80 \%\end{array}$ & 0,5 \\
\hline $\begin{array}{l}\text { Percentual de habitações com abastecimento de água entre } 40 \% \text { e } \\
60 \%\end{array}$ & 0,2 \\
\hline Percentual de habitações com abastecimento de água entre $0 \%$ e $40 \%$ & 0,0 \\
\hline
\end{tabular}

Fontes: Ribeiro (2001). 
Tabela 2 - Critérios para avaliação qualitativa por faixa de Índice de Qualidade Urbana (IQU) e/ou Índice de Qualidade de Vida Urbana (IQVU-JP)

\begin{tabular}{l|c|c|c}
\hline Classificação & Valor & Subclassificação & Valor \\
\hline \multirow{2}{*}{ ALTO } & \multirow{2}{*}{$0,800-1,000$} & Muito Alto & $0,900-1,000$ \\
& \multirow{2}{*}{ MÉDIO } & Alto & $0,800-0,899$ \\
\hline \multirow{2}{*}{ BAIXO } & $0,500-0,799$ & $\begin{array}{c}\text { Médio superior } \\
\text { Médio }\end{array}$ & $\begin{array}{c}0,650-0,799 \\
0,500-0,649\end{array}$ \\
\hline
\end{tabular}

Fonte: Ribeiro (2001)

\section{Mensuração da qualidade urbana dos objetos de estudo}

\section{Construção do Indicador de Qualidade Habitacional}

O Indicador de Qualidade Habitacional, conforme Ribeiro (2001), é o que detém peso mais relevante entre os que integram o IQVU-JP. O peso determinado pelo índice traduz a importância da habitação, já que é um dos cinco serviços públicos essenciais, ao lado de educação, saúde, segurança social e serviços sociais pessoais. Avalia a salubridade e conforto, qualidade estrutural e qualidade infraestrutural da residência a partir de três índices:

(a) Ipqhab, índice de saturação ou de pessoas por quarto;

(b) Icehab, índice de condições estruturais habitacionais; e

(c) Icihab, índice de condições infraestruturais habitacionais.

Na determinação deste indicador foi observado que todos os quesitos que medem a qualidade habitacional alcançaram pontuações máximas nos condomínios analisados. Tal constatação, por meio de visitas in loco, entrevistas e questionários ${ }^{3}$, não pode deixar de ser associada ao poder aquisitivo dos moradores, uma vez que perfazem o extrato social dos que apresentam alta renda e amplas possibilidades financeiras, além de serem alvo de um dos segmentos mais luxuosos e rentáveis do mercado imobiliário.

${ }^{3}$ Foram realizadas de três a cinco visitas aos espaços internos dos empreendimentos, que variaram de acordo com a complexidade na obtenção de dados de cada condomínio; e diversas visitas ao entorno imediato deles. Foram entregues, nas portarias de cada condomínio, de 50 a 20 questionários, a depender da taxa de ocupação, totalizando 120 questionários. No entanto, apenas 36 moradores responderam, dos quais 24 eram moradores do condomínio CBRP; oito do condomínio Villas do Farol; e quatro do condomínio Alphaville. Apenas $30 \%$ dos questionários

disponibilizados foram entregues - situação que expressa certa dificuldade para uma determinação mais consistente dos índices de habitabilidade.
Conforme Lira (2012), a maioria dos condôminos optou morar em condomínios horizontais pela oportunidade de morar em casas amplas, ao invés de apartamentos menores. Essa escolha juntamente com o poder aquisitivo dos moradores, acaba manifestando-se em forma de residências de grande porte, com estruturas e acabamentos de alto padrão.

Diante da análise, observou-se que os padrões qualitativos estruturais, infraestruturais, de conforto e de salubridade são semelhantes, independentemente do condomínio estudado. E também que, apesar de os condomínios CBRP e Villas do Farol não estarem ligados à concessionária $\mathrm{Cagepa}^{4}$, as casas são servidas com poço artesiano e fossa séptica, o que não prejudica a qualidade das instalações hidrossanitárias.

\section{Construção do Indicador de Facilidades Urbanas}

A distribuição espacial das facilidades urbanas é uma das medidas que traduz os privilégios ou déficits locacionais, bem como o nível de atendimento das necessidades básicas para atingir um limiar digno de qualidade de vida.

$\mathrm{Na}$ determinação deste indicador foi observado que as carências infraestruturais provenientes do setor onde estão instalados os condomínios do setor sul são contornadas pela intervenção do poder aquisitivo dos condôminos. A ausência de saneamento básico oferecido por uma concessionária habilitada pelo poder público e a precária cobertura dos equipamentos públicos parecem não influenciar na escolha de opção de moradia dos proprietários desses condomínios.

À vista disso, as aferições dos indicadores e índices do IQFAC ofereceram as seguintes constatações:

(a) o único quesito referente aos serviços públicos pontuado pelos condomínios do setor sul foi a coleta de lixo;

${ }^{4}$ Companhia de Água e Esgotos da Paraíba. 
(b) a maior proporção da pontuação relativa à pavimentação viária foi devido à manutenção privada;

(c) a precária cobertura de equipamentos públicos do setor sul mostra a necessidade de se deslocar por uma distância consideravelmente grande;

(d) a problemática persiste porque essa área, além de estar situada distante da malha urbana consolidada, possui recente ocupação, com poucos estabelecimentos, baixa densidade urbana e grande estoque de lotes e vazios urbanos ociosos; e

(e) o condomínio Alphaville apresenta pontuações superiores aos outros condomínios devido aos atributos locacionais da unidade urbana em que está instalado - bairro tradicional com a infraestrutura consolidada e alta densidade urbana.

Um dos indicadores secundários que aborda essa problemática locacional é o índice de proximidade de equipamentos públicos referentes à saúde, à educação e à cidadania na área de alcance dos condomínios (Ipep) ${ }^{5}$. Para a aferição deste indicador são observadas a disponibilidade e a distância do equipamento ao centroide de cada condomínio analisado. A referida metodologia entende que os equipamentos de cidadania são os equipamentos comunitários (centros sociais urbanos, equipamentos de acesso aos serviços públicos, equipamentos conviviais e de participação comunitária) que, juntamente com os demais dos sistemas de saúde, educação, segurança, formam o conjunto de equipamentos urbanos. Pode-se observar, através do mapeamento desses equipamentos, escassez de equipamentos no setor onde estão localizados os condomínios CBRP e Villas do Farol (Figura 5). Conforme a Tabela 3, os condomínios estudados adquiriram as pontuações no índice Ipep a seguir.

Diante do exposto e conforme a Tabela 4, os condomínios analisados alcançaram os indicadores de facilidades urbanas apresentados na Tabela 4.

\section{Construção do Indicador de Acessibilidades Urbanas}

Entre os elementos mais presentes e consensuais nas experiências e métodos de mensuração de qualidade de vida está a "Acessibilidade Urbana", que comporta, em média, uma importância percentual de $20 \%$ em relação ao total do índice considerado, assumindo peso imprescindível entre os indicadores. Neste item, vale salientar a diferença conceitual entre "padrão de vida", que opera de forma mais individualista e excludente, e "qualidade de vida", que se traduz de forma mais universalizada, abrangendo a população geral, em seu nível mais coletivo. Toma-se como exemplo o citado por Ribeiro (2009, p. 6):

\section{[...] uma melhoria das condições de acessibilidade e do transporte coletivo urbano, beneficia a qualidade de vida. A busca de soluções individuais como o uso do automóvel, aumenta o padrão de vida, mas não necessariamente significaria um aumento da qualidade de vida. Se todas as pessoas da cidade tivessem e usassem seus automóveis, a cidade se tornaria, inevitavelmente um caos, portanto este padrão até distanciaria da qualidade de vida e do bem estar.}

As anotações anteriores reforçaram a importância do espaço, enquanto localização, na medida em que é estimado como elemento-chave nas diferentes formas de acesso e benefícios à população e, por consequência, na escala qualitativa da vida urbana.

Os condomínios que se situam no setor sul aproveitaram-se de sua localização para induzir promoções na qualidade de vida, ao utilizar a prerrogativa de que é melhor morar em uma área próxima à natureza nativa e distante dos problemas urbanos. No entanto, na construção dos indicadores secundários e terciários do IACE, observou-se que a localização desses condomínios enfatizou alguns problemas urbanos, como as consideráveis distâncias a serem percorridas até os centros, sobretudo o principal; deficiente cobertura dos serviços de transporte público; alta dependência e incentivo à cultura automobilística; e aumento considerável do tempo médio das viagens diárias, tanto dos moradores quanto dos empregados das residências e do condomínio que utilizam o ônibus.

Por outro lado, o condomínio Alphaville, ao inserir-se em um setor urbano mais conectado com a malha urbana consolidada, apresentou melhores condições de acesso aos principais pontos elencados pela metodologia. 
Figura 5 - Cobertura de equipamentos públicos aos condomínios horizontais

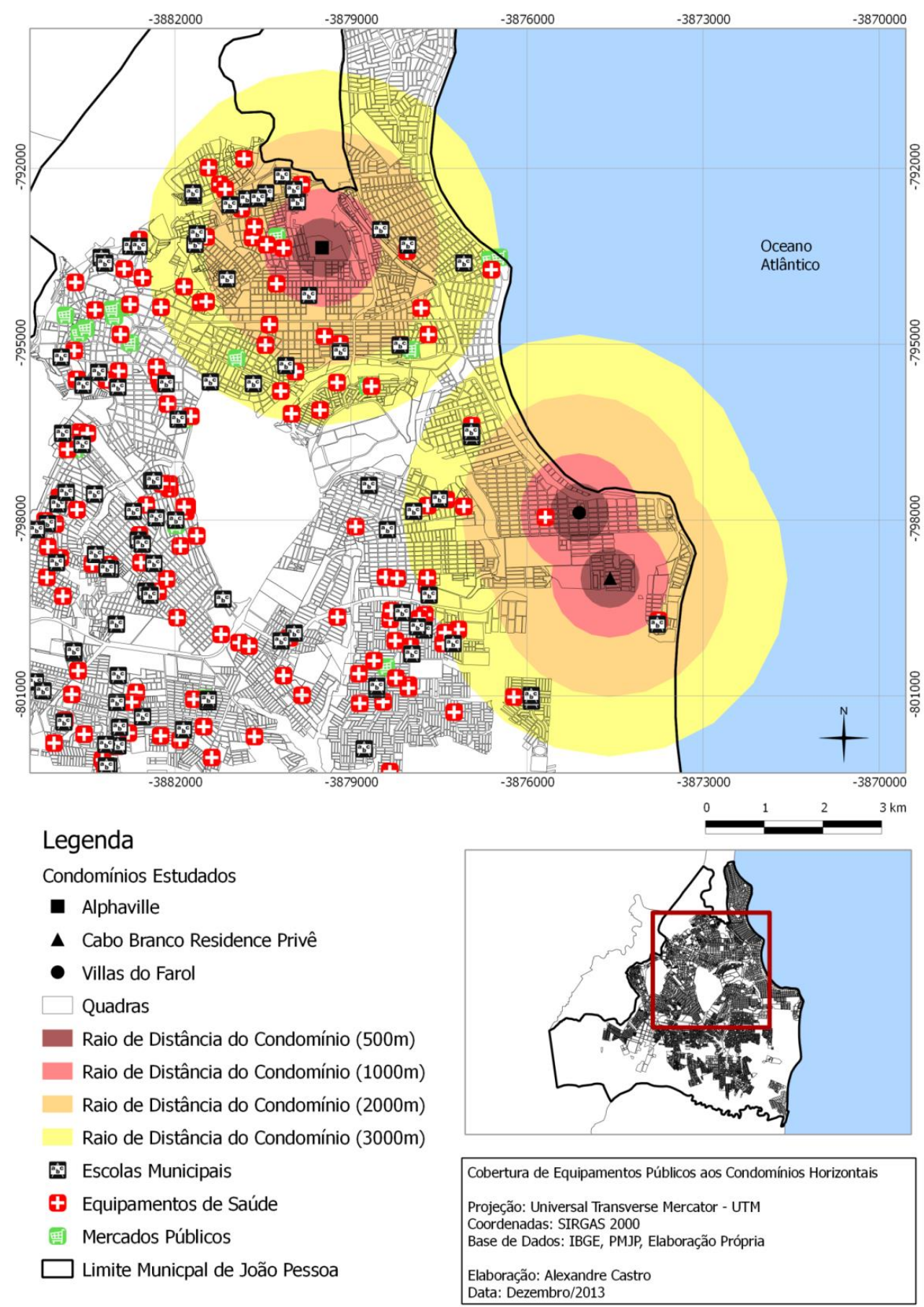

Fonte: Instituto Brasileiro de Geografia e Estatística (2013) e Prefeitura Municipal de João Pessoa (2010).

Tabela 3 - Critérios do índice de presença e proximidade de equipamentos públicos (Ipep) dos condomínios analisados

\begin{tabular}{l|c|l|l|l}
\hline $\begin{array}{c}\text { Média de distância de equipamentos } \\
\text { (saúde/educação/cidadania) }\end{array}$ & Pontuação & Alphaville & CBRP & $\begin{array}{c}\text { Villas do } \\
\text { Farol }\end{array}$ \\
\hline Média de distância menor que $500 \mathrm{~m}$ & 1,0 & & \\
M. de distância entre 500 e $1.000 \mathrm{~m}$ & 0,7 & & \\
M. de distância entre 1.001 e $3.000 \mathrm{~m}$ & 0,5 & & & \\
M. de distância entre 3.001 e $5.000 \mathrm{~m}$ & 0,2 & & & \\
M. de distância maior que $5.000 \mathrm{~m}$ & 0,0 & & & \\
\hline
\end{tabular}


Tabela 4 - Construção do IQFAC - Indicadores de facilidades urbanas dos condomínios analisados

\begin{tabular}{l|c|c|c|c|c|c}
\hline Condomínios & Iab & Ice & Icrs & Ipav & Ipep & IQFAC \\
\hline Alphaville & 1,00 & 1,00 & 1,00 & 1,00 & 0,7 & $\mathbf{0 , 9 4}$ \\
CBRP & 0,0 & 0,0 & 1,00 & 0,75 & 0.5 & $\mathbf{0 , 3 7 5}$ \\
Villas do Farol & 0,0 & 0,0 & 1,00 & 1,00 & 0.5 & $\mathbf{0 , 4 0}$ \\
\hline
\end{tabular}

Para exemplificar esse panorama, demonstra-se a obtenção do Ialz (critério de acessibilidade a áreas de lazer públicas). Apesar de cada condomínio analisado apresentar mais de $10.000 \mathrm{~m}^{2}$ de área verde e uma gama de itens de lazer, essa condição não foi avaliada para a construção desse indicador. A metodologia considera apenas praias ou parques municipais públicos, tais como o Parque Arruda Câmara e o Parque Solón de Lucena, e ainda parques de bairros com áreas superiores a 10.000 $\mathrm{m}^{2}$. Portanto, por mais que os condomínios ofereçam áreas de lazer e desportivas com potencial influenciador na qualidade de vida no quesito "promoção da saúde", são áreas privadas que não proporcionam aspectos psicossociais fundamentais na promoção da cidadania e da inserção social, sobretudo da "comunhão social" onde há, naturalmente, trocas de vivências entre pessoas de distintas classes sociais.

O condomínio CBRP encontra-se bastante próximo ao Parque Municipal Cabo Branco, a cerca de 500 metros de distância. Além disso, tanto a praia do Seixas como a do Cabo Branco são facilmente acessadas por estarem em um raio menor que $2 \mathrm{~km}$ do condomínio. Porém, os Parque Solón de Lucena e o Arruda Câmara localizam-se a quase $10 \mathrm{~km}$ de distância. O condomínio Villas do Farol se encontra em um contexto semelhante. Para o morador do condomínio Alphaville acessar alguma praia urbana ou os principais parques municipais, ele terá que atravessar cerca de $3 \mathrm{~km}$.

Diante dessa observação, a Tabela 5 apresenta a pontuação do índice Ialz.

A Tabela 6 apresenta os resultados obtidos pelo indicador de acessibilidades urbanas e dos índices que o perfazem - Iaer (indicador de acessibilidades físicas a áreas geradoras de oferta de emprego, possibilidades de renda, escolas e bens e serviços); Iabs (índice de acessibilidade ao provimento facilitado de bens e serviços); e Ialz (critério de acessibilidade a áreas de lazer públicas).

\section{Construção do Indicador de Ambiência Urbana}

Os índices que perfazem o indicador de ambiência urbana dos condomínios analisados apresentaram resultados satisfatórios. Sobre os que avaliam a qualidade do ambiente social, obtiveram-se pontuações no limiar elevado. Porém, é interessante atentar para a desigualdade social que se conforma espacialmente nos bairros Altiplano e Portal do Sol. O único condomínio que apresentou essa situação mais visível foi o condomínio Villas do Farol, pois seus vizinhos são habitações subnormais.

$\mathrm{Na}$ aferição do índice de qualidade ambiental (Iaam), por exemplo, observou-se que os condomínios não apresentaram ocorrência de degradação ambiental dentro de seu espaço interno. Porém, nos entornos imediatos dos condomínios foram apreendidos cenários compostos de terrenos baldios abandonados, demarcados por cercas sem manutenção e por vezes com presença de lixo doméstico e entulhos de construção.

A seguir, a Tabela 7 apresenta os valores obtidos pelo indicador de ambiência urbana, bem como do conjunto de índices que o compõe - Iapv (índice de proximidade ou presença sensível de parques, áreas verdes ou áreas de valor cênico e praias); Iqamb (indicador de ocorrência de elementos nocivos à qualidade ambiental); Iavt (índice de áreas verdes tratadas por habitante); Ihso (índice de homogeneidade social); e Iseg (índice de segurança urbana).

\section{Resultados e discussões IQVU do condomínio Cabo Branco
Residence Privé (CBRP)}

Em relação ao condomínio CBRP, os indicadores que mais se destacaram foram os de habitabilidade (alto pela condição socioeconômica dos moradores) e o de ambiência urbana. No entanto, dois dos três indicadores urbanos tiveram pontuações baixas, devido, principalmente, aos precários atributos locacionais (Figura 6).

O local onde está implantado o condomínio CBRP, além de carecer de equipamentos públicos e de estabelecimentos comerciais, apresenta estoque considerável de lotes ociosos, corroborando para baixa densidade urbana (antes do surgimento desses condomínios no bairro Portal do Sol, a área era composta predominantemente de ocupações subnormais). 
Tabela 5 - Critérios do índice de acessibilidade às áreas de lazer públicas dos condomínios analisados

\begin{tabular}{l|c|c|c|c}
\hline $\begin{array}{c}\text { Tempo de acesso às áreas de lazer } \\
\text { públicas }\end{array}$ & Pontuação & Alphaville & CBRP & $\begin{array}{c}\text { Villas do } \\
\text { Farol }\end{array}$ \\
\hline menor que $15 \mathrm{~m}$ (a pé) & 1,0 & & & \\
menor que 15 m a pé (c/ & 0,7 & & & \\
dificuldades) & & & & \\
menor que 15 m (ônibus) & 0,5 & & \\
menor que 15 m (automóvel) & 0,2 & & \\
maior que 15 m (automóvel) & 0,0 & & \\
\hline
\end{tabular}

Tabela 6 - Construção do IACE - Indicador de acessibilidades urbanas dos condomínios analisados

\begin{tabular}{l|c|c|c|c|c|c}
\hline Condomínios & Iaer (A) & Iaer (B) & Iaer & Iabs & Ialz & IACE \\
\hline Alphaville & 0,2 & 1,0 & 0,44 & 1,00 & 0,5 & $\mathbf{0 , 6 2}$ \\
CBRP & 0,0 & 0,5 & 0,15 & 0,2 & 1,0 & $\mathbf{0 , 3 3 5}$ \\
Villas do Farol & 0,0 & 0,5 & 0,15 & 0,2 & 1,0 & $\mathbf{0 , 3 3 5}$ \\
\hline
\end{tabular}

Tabela 7 - Construção do IAAM - Indicador de ambiência urbana dos condomínios analisados

\begin{tabular}{c|c|c|c|c|c|c}
\hline Condomínios & Iapv & Iqamb & Iavt & Ihso & Iseg & IAAM \\
\hline Alphaville & 1,00 & 0,7 & 1,00 & 1,00 & 1,00 & $\mathbf{0 , 9 1}$ \\
CBRP & 0,5 & 0,7 & 1,00 & 1,00 & 1,00 & $\mathbf{0 , 8 6}$ \\
Villas do Farol & 1,00 & 0,7 & 1,00 & 0,85 & 1,00 & $\mathbf{0 , 9 5}$ \\
\hline
\end{tabular}

Figura 6 - Gráfico demonstrando a pontuação do grupo de indicadores do IQU do condomínio CBRP

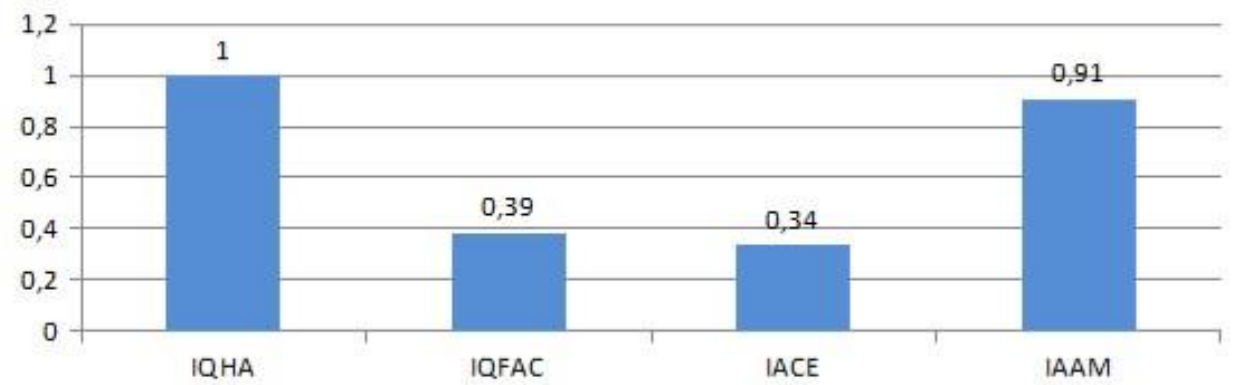

A infraestrutura de saneamento básico também foi um ponto que inferiorizou o resultado do indicador de facilidades urbanas, pois não existe abastecimento de água nem coleta de esgoto realizado pela concessionária local.

Além disso, o indicador de acessibilidade, um dos aspectos mais preocupantes, apontou serviços de transporte públicos precários e distâncias físicas e temporais a várias localidades de necessidades cotidianas, o que agrava a mobilidade dos moradores e dos funcionários do condomínio.

No entanto, o resultado do Índice de Qualidade Urbana do condomínio CBRP obteve, conforme a Equação 7, o valor de 0,651 - considerado, segundo a metodologia de Ribeiro (2001), como IQU de Médio Superior (valores entre 0,650 e 0,799).

IQU - CBRP = 0,3 $(1,0)+0,3(0,375)+0,2$ $(0,335)+0,2(0,86)=\mathbf{0 , 6 5 1}$

Eq. 7
Para a construção do IQVU deste condomínio foram utilizados os valores do IDH (2004) do bairro Portal do Sol (IDH - Educação - 0,768; IDH - Longevidade - 0,718). Dessa forma, conforme a Equação 8, o IQVU do condomínio CBRP obteve valor de 0,688 , considerado também como IQVU de Médio Superior (Tabela 8).

IQVU - CBRP $=2(0,651)+[(0,768+$

$0,718) / 2] / 3=\mathbf{0 , 6 8 1}$

Eq. 8

\section{IQVU do condomínio Villas do Farol}

Assim como o condomínio CBRP, o Villas do Farol teve seu IQU inferiorizado pelos precários valores obtidos nos indicadores urbanos, com exceção do indicador de ambiência urbana (Figura 7). Embora este último tenha pontuado dentro do limiar "alto", observaram-se agravantes relacionados à degradação ambiental e à 
homogeneidade social, devido à presença de habitações subnormais nos lotes vizinhos ao condomínio Villas do Farol.

No que concerne à qualidade habitacional, verificou-se o mesmo alto padrão observado no condomínio Cabo Branco Residence Privé.

Assim, o IQU do condomínio Villas do Farol se conforma da seguinte forma (Equação 9):

IQU-Villas do Farol $=0,3(1,0)+0,3(0,40)+0,2$ $(0,335)+0,2(0,895)=\mathbf{0 , 6 6 6}$

Eq. 9

Para a determinação do IQVU do condomínio Villas do Farol também foi utilizado o IDH do bairro Portal do Sol (IDH - Longevidade -0,718; IDH - Educação - 0,768). Assim, seu IQVU obteve a seguinte pontuação (Equação 10 e Tabela 9):

IQVU - Villas do Farol $=2(0,666)+$ $[(0,768+0,718) / 2] / 3=\mathbf{0 , 6 9 2}$

Eq. 10

\section{IQVU do condomínio Alphaville}

O condomínio Alphaville apresentou resultados diferentes dos condomínios CBRP e Villas do Farol, revelando indicadores de acessibilidade e facilidades urbanas com valores bastante superiores ao dos outros condomínios estudados (Figura 8). Isso se deve aos atributos locacionais do setor urbano onde o condomínio Alphaville está implantado, já que apresenta satisfatórios acessos urbanos aos centros principal, secundário e terciário, aos equipamentos urbanos (de saúde, educação e mercados) e infraestrutura consolidada e em boa manutenção. Os quesitos "habitabilidade" e "ambiência urbana" se manifestaram de forma semelhante aos demais condomínios, atingindo um limiar bastante satisfatório.

Tabela 8 - Valores dos indicadores, do IQU e do IQVU do condomínio CBRP

\begin{tabular}{|c|c|c|c|c|c|c|c|}
\hline \multirow{2}{*}{ Condomínio } & \multicolumn{4}{|c|}{ Indicadores do IQU } & \multirow[t]{2}{*}{ IQU } & \multirow[t]{2}{*}{ IQVU } & \multirow[t]{2}{*}{ Classificação } \\
\hline & IQHA & IQFAC & IQACE & IAAM & & & \\
\hline CBRP & 1,000 & 0,375 & 0,335 & 0,860 & 0,651 & 0,681 & Médio Superior IQVU \\
\hline
\end{tabular}

Figura 7 - Gráfico demonstrando a pontuação do grupo de indicadores do IQU do condomínio Villas do Farol

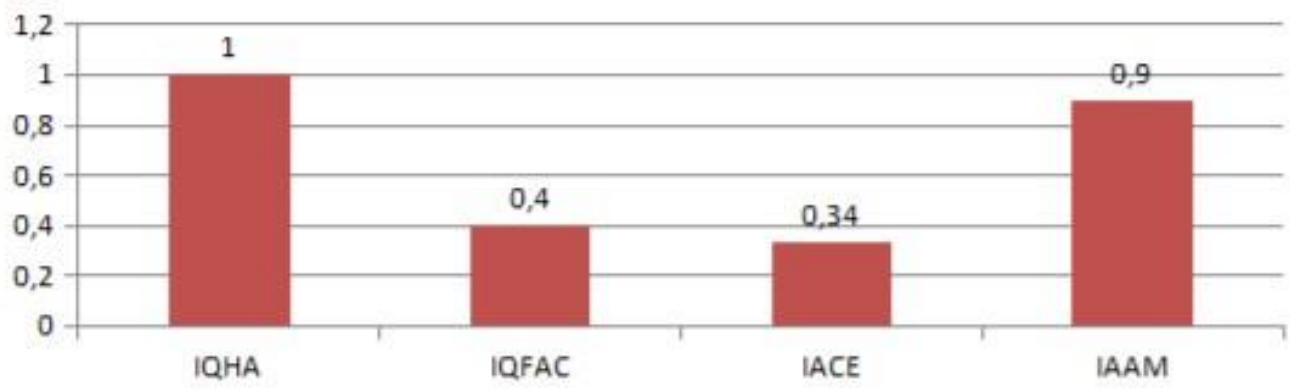

Tabela 9 - Valores dos indicadores, do IQU e do IQVU do condomínio Villas do Farol

\begin{tabular}{c|c|c|c|c|c|c|c}
\hline \multirow{2}{*}{ Condomínio } & \multicolumn{4}{|c|}{ Indicadores do IQU } & \multirow{2}{*}{ IQU } & \multirow{2}{*}{ IQVU } & \multirow{2}{*}{ Classificação } \\
\cline { 2 - 5 } & IQHA & IQFAC & IQACE & IAAM & & \\
\hline Villas do Farol & 1,000 & 0,400 & 0,335 & 0,895 & $\mathbf{0 , 6 6 6}$ & $\mathbf{0 , 6 9 2}$ & Médio Superior IQVU \\
\hline
\end{tabular}


Figura 8 - Gráfico demonstrando a pontuação do grupo de indicadores do IQU do condomínio Villas do Farol

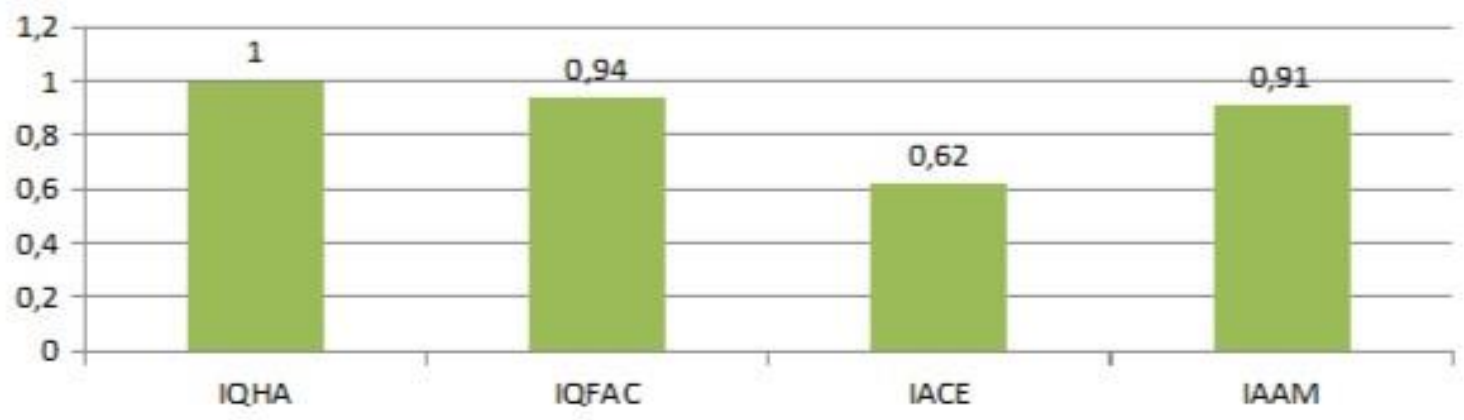

Tabela 10 - Valores dos indicadores, do IQU e do IQVU do condomínio Alphaville

\begin{tabular}{|c|c|c|c|c|c|c|c|}
\hline \multirow{2}{*}{ Condomínio } & \multicolumn{4}{|c|}{ Indicadores do IQU } & \multirow[t]{2}{*}{ IQU } & \multirow[t]{2}{*}{ IQVU } & \multirow[t]{2}{*}{ Classificação } \\
\hline & IQHA & IQFAC & IQACE & IAAM & & & \\
\hline Alpahville & 1,000 & 0,940 & 0,620 & 0,910 & $\mathbf{0 , 8 8 8}$ & $\mathbf{0 , 8 8 5}$ & Alto IQVU \\
\hline
\end{tabular}

Figura 9 - Gráfico comparativo mostrando a pontuação do IQU dos condomínios analisados

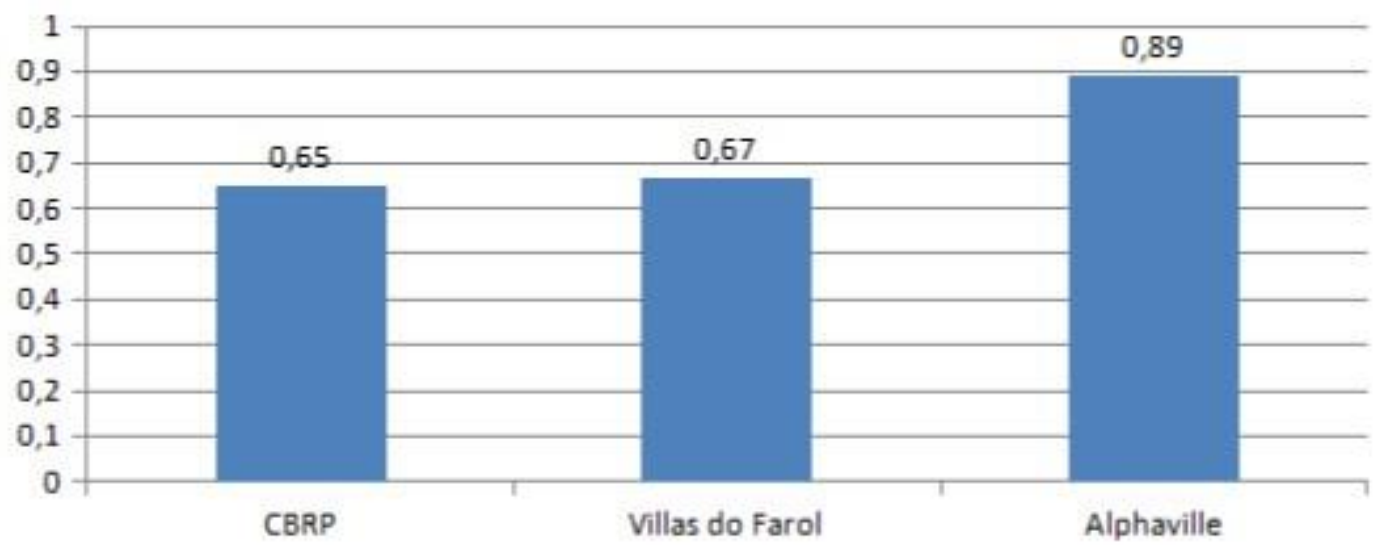

O IQU do condomínio Alphaville foi o único dos condomínios estudados a obter a classificação de “Alto IQU”, com a pontuação de 0,888 . Da mesma forma comportou-se seu IQVU, com o valor de 0,885. Para o cálculo do IQVU (Equações 11 e 12 e Tabela 10), foi utilizado o IDH do bairro dos Estados (Educação obteve o valor 0,959, e o referente à Longevidade, 0,803).

IQU - Alphaville = 0,3 $(1,00)+0,3(0,94)+0,2$ $(0,62)+0,2(0,91)=\mathbf{0 , 8 8 8}$

Eq. 11

IQVU - Alphaville $=2(0,888)+[(0,959+$ $0,803) / 2] / 3=\mathbf{0 , 8 8 5}$

Eq. 12

\section{Comparativo entre os Índices de Qualidade de Vida Urbana dos condomínios estudados}

Em relação ao indicador de habitabilidade observou-se que este apresenta considerável influência da condição social e do poder aquisitivo do morador, pelo fato de a unidade habitacional ser um bem particular. Assim, em todos os condomínios, o indicador habitacional se revelou no limiar mais alto elencado pela metodologia, pois os moradores conformam-se como classe alta e com possibilidades de ter e manter residências com boa infraestrutura e estrutura, além de padrão construtivo de qualidade. 
Figura 10 - Comparativos dos subíndices que perfazem o conjunto de indicadores do IQU dos condomínios analisados

Comparativo entre os subíndices do Indicador de Habitabilidade dos condomínios analisados

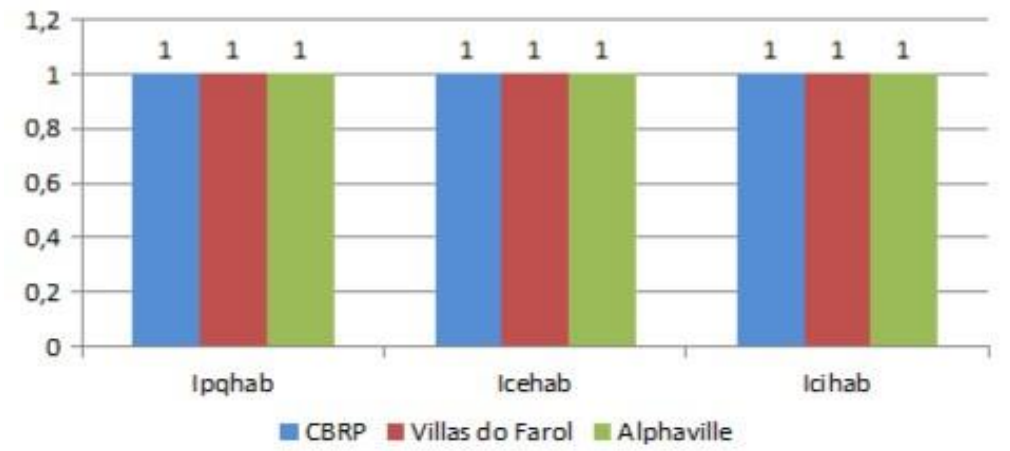

Comparativo entre os subíndices do Indicador de Facilidades Urbanas dos condomínios analisados

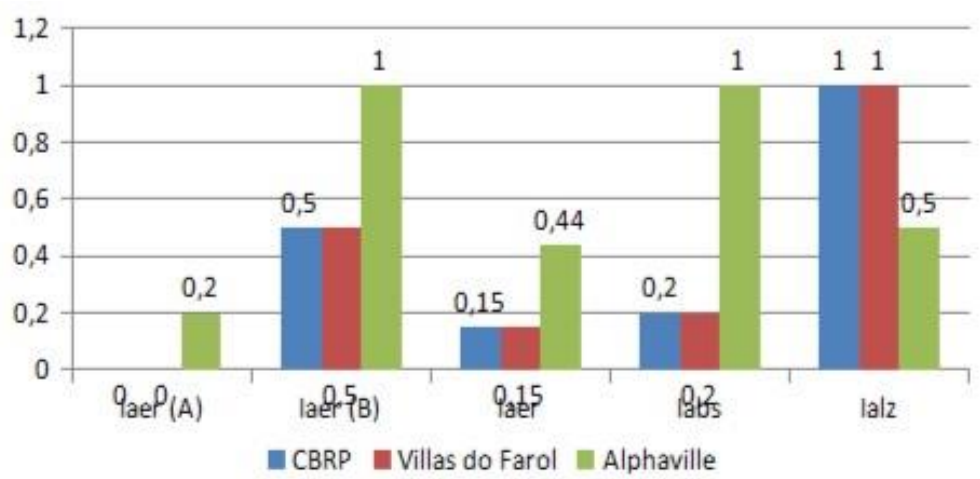

Comparativo entre os subíndices do Indicador de Acessibilidade Urbana dos condomínios analisados

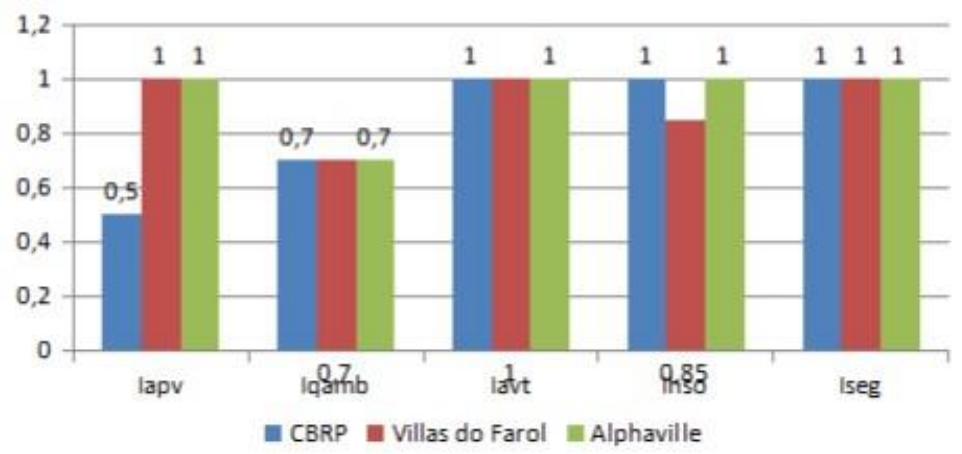

Comparativo entre os subíndices do Indicador de Ambiência Urbana dos condomínios analisados

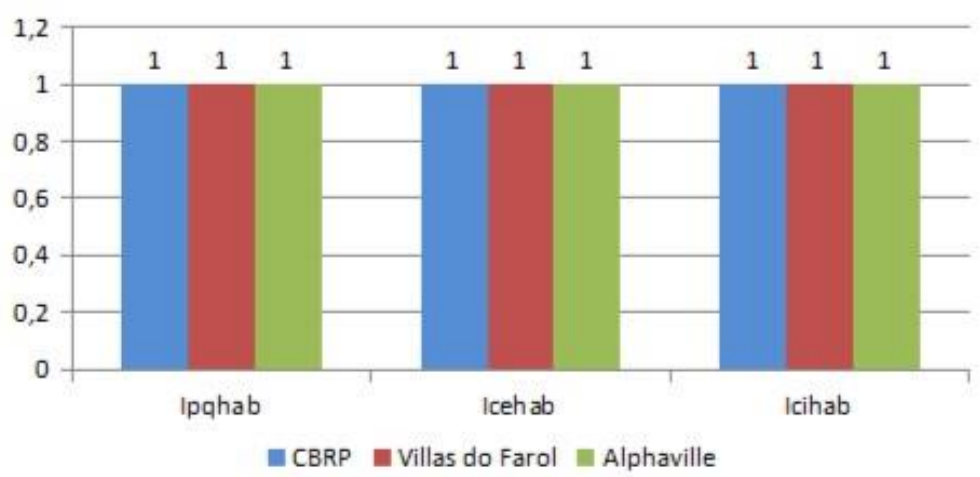


O diferencial que influenciou na qualidade urbana e, consequentemente, na qualidade de vida urbana dos condomínios analisados foi a localização. A qualidade de vida apresenta estreito relacionamento com o espaço físico. Conforme Villaça (2001), a localização define-se como a reunião de atributos locacionais de um ponto do território, que definem suas possibilidades de relacionamento com os demais pontos desse território.

É interessante vincular o conceito de qualidade de vida urbana à localização, tendo em vista que a prática social urbana e as atividades cotidianas são estruturadas espacialmente a partir da localização residencial (BARROS, 1999), que é o ponto de partida de qualquer citadino para exercer as atividades do dia a dia.

Os gráficos das Figuras 9 e 10 ratificam tal importância, mostrando o comparativo entre os subíndices dos indicadores de acessibilidade e facilidades urbanas, que, por suas vezes, avaliam o contexto físico e urbano da localização.

Quando analisados os condomínios CBRP e Villas do Farol, observaram-se agravantes nos atributos relacionados à infraestrutura de saneamento básico, equipamentos urbanos e acessos aos centros (principal, secundário e terciário). Já, quando avaliado o condomínio Alphaville, tais atributos foram aferidos de forma positiva, pois sua localização dispunha de praticamente todos os quesitos elencados pela metodologia.

Por fim, no que concerne à ambiência urbana, outro atributo locacional, os condomínios obtiveram valores semelhantes. Os condomínios do setor sul são beneficiados com a presença de um parque com mais de $10.000 \mathrm{~m}^{2}$ (Parque Cabo Branco Altiplano), além da proximidade de praias urbanas e áreas verdes inseridas nos próprios condomínios. O condomínio Alphaville apresenta realidade diferente, pois está inserido em um setor com grande densidade urbana, porém se observou em seu entorno a presença de praças de porte pequeno e uma área de valor cênico dentro do empreendimento (área de valor cultural requalificada - Fazenda Boi Só).

A Figura 11 apresenta um comparativo entre os Índices de Desenvolvimento Humano referentes à
Educação e à Longevidade dos bairros onde os condomínios estão inseridos. Dentro da fórmula do IQVU-JP, tais índices têm peso relativamente menor $(0,5)$, quando comparados ao IQU, que tem peso 2. Ao aplicar o valor destes índices percebeuse tênue modificação no valor, resultando algumas diferenças entre a pontuação do IQU e a do IQVU.

Neste sentido, o condomínio CBRP, que tinha IQU de 0,651, após a inserção dos indicadores do IDH, foi beneficiado em 0,030 pontos, obtendo IQVU de 0,681. O mesmo ocorreu com o condomínio Villas do Farol, que obteve 0,666 no IQU e 0,692 no IQVU. No entanto, com relação ao condomínio Alphaville, o IDH acabou influenciando negativamente, pois os indicadores de qualidade urbana apresentavam pontuação superior $(0,888)$ do que quando inseridos os índices do IDH, conformando IQVU de 0,885 .

Conforme observado, o condomínio Alphaville apresentou os maiores IQU e IQVU entre os condomínios estudados (Tabela 11). O valor do seu IQU, considerado como alto, se assemelha aos índices obtidos pelos bairros elencados pelo "Monitoramento Contínuo da Qualidade de Vida Urbana de João Pessoa - PB (2004-2008)", como de maior IQU, a exemplo do próprio Bairro dos Estados $(0,869)$ - onde está inserido. O IQU do condomínio Alphaville foi, inclusive, superior ao bairro onde está inserido. Os indicadores de Habitabilidade, de Facilidades e Acessibilidades Urbanas do Alphaville e do B. dos Estados são semelhantes entre si, porém o de Ambiência Urbana do condomínio se revelou superior devido a seu percentual de área verde por habitante e pela presença de um patrimônio de valor cultural.

\section{Considerações finais}

Com a aferição da qualidade urbana para posterior obtenção do Índice de Qualidade de Vida Urbana dos condomínios selecionados, perceberam-se duas situações distintas:

(a) a dos condomínios CBRP e Villas do Farol, que se localizam no mesmo bairro; e

(b) a do condomínio Alphaville, que está implantado no Bairro dos Estados. 
Figura 11 - Gráfico comparativo mostrando a pontuação do IQVU dos condomínios analisados

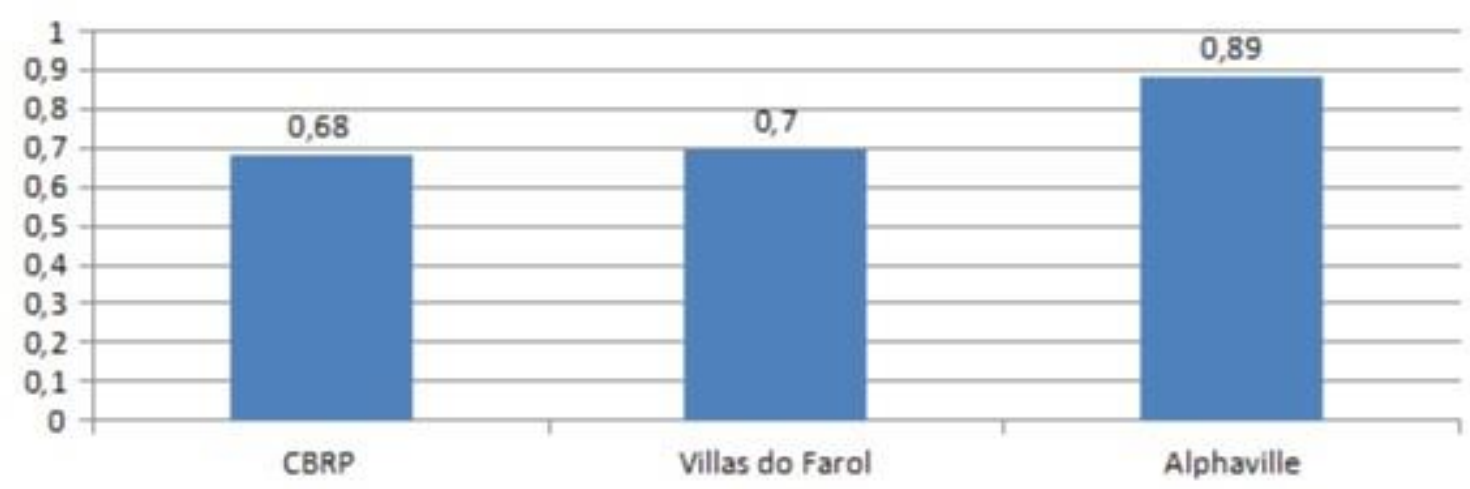

Tabela 11 - Valores do IQU e do IQVU dos condomínios analisados

\begin{tabular}{l|c|l|l}
\hline Condomínio & IQU & IQVU & $\begin{array}{c}\text { Classificação do } \\
\text { IQVU }\end{array}$ \\
\hline CBRP & 0,661 & 0,681 & Médio Superior \\
Villas do Farol & 0,666 & 0,692 & Médio Superior \\
Alphaville & 0,888 & 0,885 & Alto \\
\hline
\end{tabular}

No primeiro caso, foram observados ótimos índices de habitabilidade, satisfatórios índices de ambiência urbana e precários índices de acessibilidade e facilidades urbanas, atribuindo a estes condomínios uma qualidade urbana média, igualando-os a bairros medianos com baixa valoração imobiliária e sem "status". Entretanto, se fossem considerados apenas os índices urbanos, excluindo o índice relacionado à habitação (alto pela excelente condição socioeconômica dos moradores), os condomínios iriam obter índices bastante baixos, dignos de áreas carentes.

A aferição da qualidade urbana do condomínio Alphaville se revelou bem superior, principalmente nos quesitos de facilidades urbanas e de acessibilidade, pelo fato de estar mais conectado à rede infraestrutural e de equipamentos públicos da cidade.

A partir do Indicador de Facilidades Urbanas observaram-se as deficiências e os privilégios locacionais, distinguindo os condomínios em termos de usufruição da infraestrutura e de equipamentos públicos. Constatou-se que nos condomínios CBRP e Villas do Farol tais deficiências foram contornadas pelos aparatos tecnológicos advindos do poder aquisitivo de seus moradores.

Essa situação ratifica mais uma vez a diferença entre "padrão de vida" e "qualidade de vida", já que o atendimento desta última, como ressalta
Ribeiro (2009), se obtém por intermédio da capacidade interna das estruturas e do aparato urbano, corroborando a importância da relação com a cidade.

$\mathrm{O}$ mesmo ocorre em termos de acessibilidade. $\mathrm{Na}$ metodologia adotada, pelo fato de o Indicador de Acessibilidade estar ajustado a uma conduta mais sustentável e à equidade social, conferindo maior pontuação aos modais "a pé" e "transporte público", constatou-se deficiente acessibilidade aos locais onde ocorre a vida urbana - centros principal, secundário e terciário.

De forma geral, os valores obtidos na qualidade de vida urbana dos condomínios (Médio Superior para os condomínios CBRP e Villas do Farol e Alto para o condomínio Alphaville) atentam para a importância da localização e de sua relação com os demais espaços da cidade. Atestam também que, ao contrário do que é induzido pelos atores sociais envolvidos na proliferação destes empreendimentos ao enobrecer áreas isoladas física e socialmente, a qualidade de vida se manifesta de forma efetiva quando se tem acesso à cidade. Segundo Vitte e Keinert (2009), em seu livro "Qualidade de vida, planejamento e gestão urbana", a cidade como lugar é uma condição de realização da vida cotidiana, que resulta de uma relação do indivíduo com a cidade e exerce influência direta na qualidade de vida. 


\section{Referências}

ANDRADE, P. A. de; VIDAL, W. Realidade Urbana e Legislação Municipal: expansão de condomínios residenciais fechados em João Pessoa. Vitruvius, São Paulo, v. 12, n. 140.04, jan. 2012.

ALMEIDA, A. C. de M. A Qualidade de Vida no Estado do Rio de Janeiro. In: ENCONTRO NACIONAL DA ANPUR, 7., Recife, 1997. Anais... Recife: UFPE, 1997.

BARROS, J. Espacialidade e Crescimento: a produção do espaço urbano sob o capitalismo. Porto Alegre, 2001. Dissertação (Mestrado em Planejamento Urbano e Regional) - Programa de Pós-Graduação em Planejamento Urbano e Reginal, Porto Alegre, 1999.

BUARQUE, C. Qualidade de Vida: a modernização da utopia. Lua Nova, v. 31, p. 157 165, maio 1993.

CALDEIRA, T. Cidade de Muros: crime, segregação e cidadania em São Paulo. São Paulo: Editora 34, 2000.

CRUZ, P. C. e S.; MORAIS, M. T. Urbanidades do Bairro Altiplano Cabo Branco, João Pessoa/PB: verticalização e materialização das cidades brasileiras. In: ENCONTRO DA ASSOCIAÇÃO NACIONAL DE PESQUISA E PÓSGRADUAÇÃO EM ARQUITETURA E URBANISMO, 4., Porto Alegre, 2016. Anais... Porto Alegre. 2016.

EL DIN, H. S. et al. Principles of Urban Quality of Life for a Neighbourhood. HBRC Journal, v. 9, n. 1, p. 86-92, 2013.

HASANI, N. A.; MOSAYEBI, S.; HASANI, N., A. Assessing the Quality of life indicators in urban neighborhoods (Case study: Haji Abad, Fars).

Journal of Geography and Regional Development, v. 14, p.165-184, 2016.

INSTITUTO BRASILEIRO DE GEOGRAFIA E ESTATÍSTICA. Metodologia do Censo Demográfico 2010. Rio de Janeiro: IBGE, 2013.

LEITE, C.; AWAD, J. di C. M. Cidades Sustentáveis, Cidades Inteligentes: desenvolvimento sustentável num planeta urbano. Porto Alegre: Bookman, 2012.

LIRA, A. H. C. de. O Fenômeno dos Condomínios Horizontais da Cidade de João Pessoa - PB. João Pessoa, 2012. Dissertação (Mestrado em Engenharia Civil) - Escola de Engenharia, Universidade Federal da Paraíba, João Pessoa, 2012.
MATSUI, H. K. M. Sistema de Avaliação de Qualidade de Vida Urbana: espaços e fronteiras da modelagem da informação da cidade (CIM). In: ENCONTRO DE ASSOCIAÇÃO NACIONAL DE PESQUISA E POS-GRADUÇÃO EM ARQUITETURA E URBANISMO, 4., Porto Alegre, 2016. Anais... Porto Alegre, 2016.

NAHAS, M. I. P. et al. Indice de Qualidade de Vida Urbana de Belo Horizonte: um instrumento intra urbanístico de gestão da qualidade de vida. In: ENCONTRO NACIONAL DA ANPUR, 7., Recife, 1998. Anais... Recife, 1998.

NAHAS, M. I. P. Planejamento Público e Indicadores Sociais. Curitiba: Secretaria de Estadodo Planejamento e Coordenação Geral. Instituto Paranaense de Desenvolvimento Econômico e Social, 2005.

NAHAS, M. Índice de Mobilidade Sustentável Para Avaliar a Qualidade de Vida Urbana: estudo de caso região metropolitana de Porto Alegre - RMPA. Porto Alegre. 2011. Dissertação (Mestrado em Arquitetura) - Escola de Engenharia, Universidade Federal do Rio Grande do Sul, Porto Alegre, 2011.

PREFEITURA MUNICIPAL DE JOÃO PESSOA. Secretaria de Planejamento. Diretoria de Geoprocessamento e Cadastro Urbano. João Pessoa, 2010.

REIS, N. G. Notas Sobre Urbanização Dispersa e Novas Formas de Tecido Urbano. São Paulo: Via das Artes, 2006.

RIBEIRO, E. L. Qualidade de vida Urbana: indicadores e estudos da percepção coletiva. João Pessoa: [s.n.], 2001.

RIBEIRO, E.L. Cidades (in)Sustentáveis: reflexões e busca de modelos urbanos de menor entropia. João Pessoa: Editora Universitária UFPB, 2006.

RIBEIRO, E. L. Monitoramento Contínuo da Qualidade de Vida Urbana em João Pessoa (2004-2008). João Pessoa: Prefeitura Municipal de João Pessoa, 2009.

SANTOS, L. D.; MARTINS, I. Monitoring Urban Quality of Life: the Porto experience. Social Indicators Research, v. 80, p. 411-425, 2007.

VILLAÇA, F. Espaço Intra-Urbano no Brasil. São Paulo: Studio Nobel, 2001.

VITTE, C. C. S.; KEINERT, T. M. M. Qualidade de Vida, Planejamento e Gestão Urbana:

discussões teórico-metodológicas. Rio de Janeiro: Bertrand Brasil, 2009. 
WILHEIM, J. O Substantivo e o Adjetivo. 3. ed.

São Paulo: Perspectiva, 2003.

Anneliese Heyden Cabral de Lira

Curso de Arquitetura e Urbanismo | Faculdades Integradas de Patos | Rua Horácio Nóbrega, lado par, Belo Horizonte | Patos - PB - Brasil | CEP 58704-000 | Tel.: (83) 3421-2742 | E-mail: anne_heyden@hotmail.com

\section{José Augusto Ribeiro da Silveira}

Centro de Tecnologia, Departamento de Arquitetura | Universidade Federal da Paraíba | Campus Universitario, s/n, Campus I, Cidade Universitaria, Conjunto Castelo Branco | João Pessoa - PB - Brasil | CEP 58051-900 | Tel.: (83) 3216-7601 Ramal 7601 | E-mail: ct.laurbe@gmail.com

\section{Edson Leite Ribeiro}

Secretaria Nacional da Habitação | Ministério das Cidades | Quadra 1, Lotes 01/06, Bloco H, Edificio Telemundi II, Sala 1105, SAUS - Plano Piloto | Brasília - DF - Brasil | CEP 70070-010 | Tel.: (61) 2108-1154 Ramal 1154 | E-mail: edlribeiro@gmail.com

\section{Milena Dutra da Silva}

Laboratório de Análise da Vegetação em Ambiente Natural e Construído | Universidade Federal de Alagoas | Av. Beira Rio, s/n, Centro Histórico | Penedo - AL - Brasil | CEP 57200-000 | Tel.: (82) 3214-5000 | E-mail: dutra_ms@hotmail.com

\section{Luciana Andrade dos Passos}

Departamento de Arquitetura, Centro de Tecnologia | Universidade Federal da Paraíba | Tel.: (83) 3216-7115 | E-mail:

lucianadospassos@hotmail.com

\section{Revista Ambiente Construído}

Associação Nacional de Tecnologia do Ambiente Construído

Av. Osvaldo Aranha, $99-3^{\circ}$ andar, Centro

Porto Alegre - RS - Brasil

CEP $90035-190$

Telefone: +55 (51) 3308-4084

Fax: +55 (51) 3308-4054

www.seer.ufrgs.br/ambienteconstruido

E-mail: ambienteconstruido@ufrgs.br 